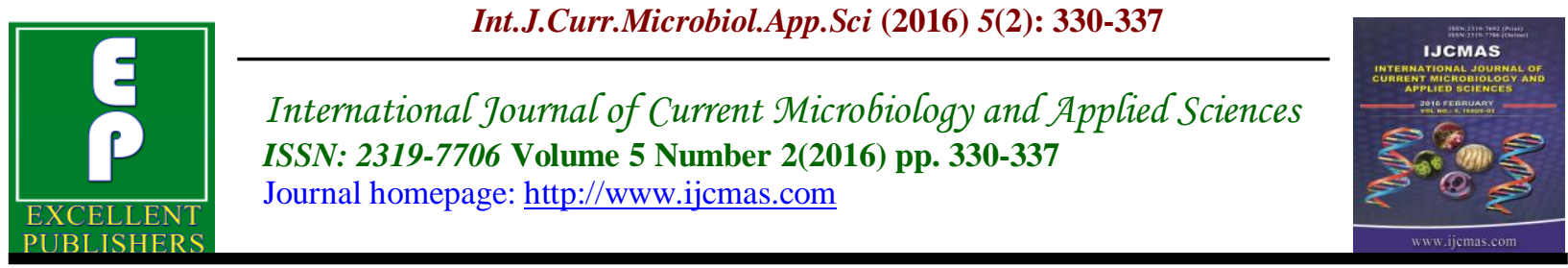

Original Research Article

doi: http://dx.doi.org/10.20546/ijcmas.2016.502.038

\title{
Pattern of Malaria Infection at Tertiary Care Hospital of Haryana-A Hospital Based Study
}

\author{
Ruby Naz ${ }^{1}$, Mohammad Khalid Farooqui ${ }^{2 *}$, Ruchi Girotra ${ }^{1}$ and A. K. Malik ${ }^{1}$ \\ ${ }^{1}$ Department of Microbiology, SHKM GMC Mewat, Haryana, India \\ ${ }^{2}$ Department of ENT, SHKM GMC Mewat, Haryana, India \\ *Corresponding author
}

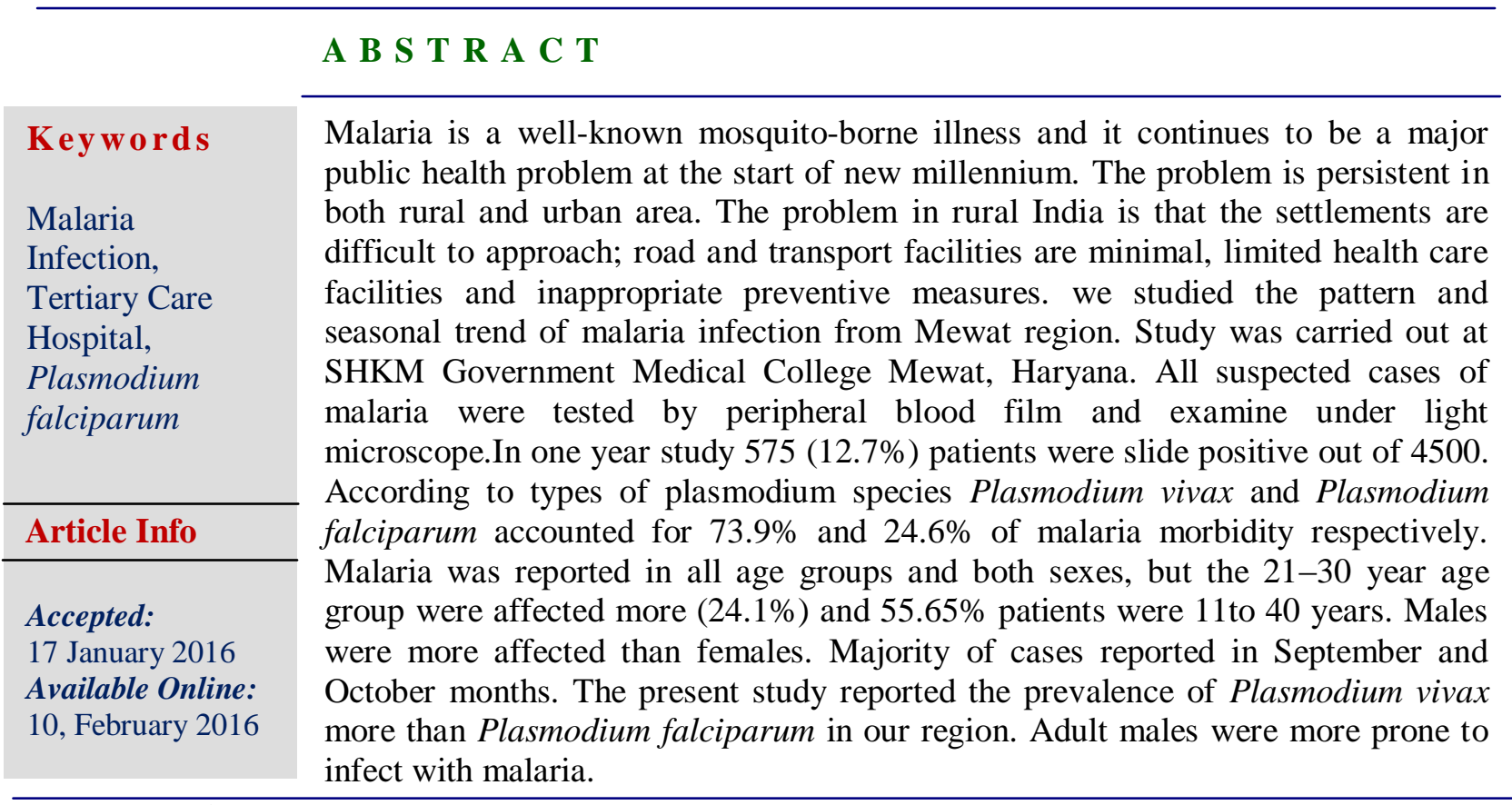

\section{Introduction}

Malaria is common mosquito-borne illnesses in our country. It is a protozoan disease caused by the parasites of the genus plasmodium. Common species in India are Plasmodium vivax, Plasmodium malariae, Plasmodium falciparum, and Plasmodium ovale. Sporozoite of Plasmodium is transmitted by the bite of female Anopheles mosquitoes commonly from dusk to dawn. (Swetha et al., 2015).

A typical attack comprises of three stages such as cold stage, hot stage and sweating stage and showing symptoms such as head ache, fever, shivering, vomiting, haemolytic anaemia, jaundice, haemoglobin in urine, retinal damage and convulsions.(Chatterjee KD et al., 2009)

Plasmodium vivax and Plasmodium falciparum are commonly seen the tropical countries like Africa, India Pakistan, Afghanistan, Shri Lanka, Middle East and South East Asia, Plasmodium Malariae and 
Plasmodium Ovale are less common cause of disease and generally do not cause severe illness. (Park K et al., 2002)

It is estimated that a cumulative 1.2 billion fewer malaria cases and 6.2 million fewer malaria deaths occurred globally between 2001 and 2015 than would have been the case had incidence and mortality rates remained unchanged since 2000. Of the estimated 6.2 million fewer malaria deaths between 2001 and 2015, about 5.9 million $(95 \%)$ were in children aged under 5 years. These deaths represent $13 \%$ of the 46 million fewer deaths from all causes in children aged less than 5 years since 2000 (assuming under-5 mortality rates in 2000 remained unchanged during 2000-2015). More than $90 \%$ of malaria is caused by $P$. vivax and $P$. falciparum. It is one of the leading causes of illness and death in the world (World Malaria Report 2015). Severe malaria caused by Plasmodium falciparum is associated with fatal complications such as cerebral malaria, algid malaria, septicemic malaria, severe anemia, kidney failure, respiratory distress, metabolic acidosis. (Verma $\mathrm{P}$ et al., 2014)

In tropical countries such as India, malaria may be throughout the whole year but higher in autumn and spring. (Alemu et al., 2012) Owing to existence of an ideal environment for the breeding of mosquitoes such as warm climate, heavy rain, and stagnant water, industrialization, and expanding urbanization are the factors attributed toward the mosquito breeding. ${ }^{7}$ The incidence of malaria peaks in monsoon (June to October), as stagnant water provides the optimal conditions for the breeding of mosquitoes. In India, National Vector-Borne Disease Control Program (NVBDCP) auspices the control measures for malaria that should be vertically implemented all over the nation. The most endemic Malarious regions in India are Central and Eastern Indian regions of the country covering Madhya Pradesh, Jharkhand, Chhattisgarh, Orissa, West Bengal and Assam.(Aruna et al., 2004)

The present study was planned to observe the occurence and pattern of malarial infection and socioeconomic factor at a tertiary care hospital in Mewat region. A constant watch on the changing pattern of the diseases provides us an opportunity for timely intervention as well as monitor the progress of the ongoing disease control programs.

\section{Materials and Methods}

The present was carried out as seasonal variations and pattern of malaria infection at Mewat region (Atif et al., 2000).

\section{Study Area}

Research laboratory of Microbiology department of SHKM GMC Mewat, Haryana

Duration: one year study was done on 4500 blood samples from January 2015 to December 2015

\section{Inclusion Criteria}

Outdoor and indoor patients from various departments of SHKM GMC Mewat presented with sign and symptoms suggestive of malaria. Clinical diagnosis based on fever (temperature $>37.5^{\circ} \mathrm{C}$ ) and/or history of fever (3-17 days), and other symptoms including; headache, joint pains, body weakness, cough, diarrhoea, loss of appetite/refusal of feeds, abdominal pain, and generalized body weakness was carried out by physicians at the outpatient and inpatient department of the hospital. 


\section{Exclusion criteria}

1. Patients took any anti-malarial within a week

2. HIV positive or any other immunological disorder

3. Febrile patients with other possible alternative cause

4. Patients of acute febrile illness with negative MP on peripheral blood film on three consecutive samples.

\section{Methodology}

All of the samples obtained in Parasitology laboratory were tested by peripheral blood film and examine under light microscope using 100X oil immersion. The smears were processed by fixing the thin film in absolute methanol (methyl alcohol), heat fixed and stained with $10 \%$ Giemsa solution in buffered water, $\mathrm{pH} 7.2$ for 10-12 min. After staining, the smears were rinsed with normal water, drained and air dried. They were then examined by light microscopy under 1000x magnification for malaria parasites, Plasmodium species. A malaria blood film was considered negative after 100 high power fields had been examined.(Chatterjee et al., 2009)

\section{Results and Discussion}

4500 patients with symptom suggestive of malaria were screened,out of which $575(12.7 \%)$ were found slide positive for malaria parasite. Plasmodium vivax found in $73.9 \%$ cases and Plasmodium falciparum found in $24.6 \%$ cases. Mixed infection acquired by $1.91 \%$ cases.

In present study males were $54.43 \%$ and females were $45.5 \%$. The malaria was predominently obsereved among adults (11 to 40 years) contituting $55.6 \%$ cases. Majority of patients came from rural area of mewat most of victims were uneducated and they belonged to lowere class families. $74.9 \%$ patients were from OPD and $25 \%$ were from IPD (Table No.1).

There was a fluctuating seasonal trend of malaria during a year, as there was a complete absence of microscopically confirmed malaria cases being reported from February to June, and the maximum cases were reported from August to November, with a peak in October (Table No. 2).

In our study maximum number of cases was from August to November. Parasite rises soon after the start of the first rain season in July reaching peak in September and October because the rains provide good breeding sites for mosquito vectors. As vector population increases, transmission of infection subsequently rises. As rainfall decreases and breeding grounds of mosquito vector dries up at the end of the rain season around October, then falls reaching a minimum after November, probably due to a reduction in mosquito vector population. Many investigators reported seasonal trends of malaria in tropical countries like India. Mewat belt is associated with unusual monsoon rains and other socio-economic factors, changing the malaria scenario at an interval of 7-9 years.(Aruna et al., 2004)

The present study findings were similar to other investigators. Tropical countries are humid and warm in rainy season. . For most Anopheles vector species of malaria, the optimal temperature range for their development lies within $20^{\circ} \mathrm{C}$ to $30^{\circ} \mathrm{C}$. However, transmission of Plasmodium vivax requires a minimum average temperature of $15^{\circ} \mathrm{C}$ and transmission by Plasmodium falciparum, requires a minimum temperature of $19^{\circ} \mathrm{C}$. That may be a reason for more cases of malaria during October or November month.(Amit et al., 2012)(Suman et al., 2006; Joel JJ et al., 2013) 
Since most of the patients in Mewat were poor they live in mud plastered houses (Katcha ghar) and sleep in open spaces in fields, prone to bite by mosquitoes. In addition improper disposal of excreta and stagnant water around house working in fields bare footed, bare body major factor to spread of malaria. Majority of people are uneducated, lack of health facility and poor they were not aware about malaria they didn't take appropriate preventive measures. It worsens the condition of patients and increases the severity of malaria. Other investigators also reported that malaria more common in poor living standards (Amit et al., 2012).

Males $(54.4 \%)$ were more than female $(45.5 \%)$. The present study results were similar to other investigators. A study from Kerala also support that malaria infection in males is higher compared to females (Chandrashekar et al., 2011). A hospital based study conducted at KMC hospital, in India also supports high preponderance of males in malaria case infection (Chowta et al., 2007). Study by Praveen et al., from Rajasthan reported a much difference males were more affected than female similar to our study behind it may be in this region male were more engaged in outdoor activities and fields work so, it makes them more prone to mosquito bites (Kumar $\mathrm{P}$ et al., 2010). Other studies also reported similar findings (Balpande et al., 2014; Preetam et al., 2012; Amit et al., 2012).

Maximum patients were from age group 21$30 \mathrm{yr}(24.17 \%)$ followed by $1-10 \mathrm{yr}$ (21.04\%). 55.6\% patients were adult from 11-40 yr, these findings might be associated with their daily outdoor activities for job, farming, etc., which expose them to the bite of mosquitoes. Similar results were found in other studies also.(Kumar $\mathrm{P}$ et al., 2010) Study by Amit et al., from Gujarat reported maximum cases from age group less than 15 years and Balpande et al., reported most common affected group 11-2-0 years. Difference may be due to difference in area and they club age groups.

In the present study Plasmodium vivax were $73.9 \%$ and Plasmodium falciparum were $24.6 \%$ Frequency of P. Vivax $(73.9 \%)$ cases was remarkably high with, while the study conducted by I Jamaiah et al., (2006) they found Plasmodium falciparum was the most common species $(57 \%)$ reported in their study followed by Plasmodium vivax $(38 \%)$ and $5 \%$ mixed infection.

There are various studies from various geographical area reported different pattern of malaria. In some studies found more cases of Plasmodium vivax while other reported more cases of Plasmodium falciparum. Table no. 3 showed comparison of various studies. Madhu Muddaiah et al., in their study on malaria in South Canara, Karnataka states also reveals that Plasmodium vivax constitutes as highest; $52.54 \%$, Plasmodium falciparum $33.75 \%$ and mixed malarial infection is $13.69 \%$ (Muddaiah M et al., 2006). Similar findings also reported in the study of Swetha et al., 95.83\% cases were Plasmodium vivax $4.13 \%$ were Plasmodium falciparum (Swetha et al., 2015). The other studies conducted in different states of India on this regard also second the preponderance of Plasmodium falciparum. Gauravi Mishra in their study of malaria in Ratnagiri district, reports the $59.09 \%$ of infection was due to Plasmodium falciparum.(Gauravi et al., 2003). Nadjm et al., in their study on 'Malaria an update for physicians' also support that more infections happens due to Plasmodium falciparum because Plasmodium falciparum constitutes $75 \%$ of infection while Plasmodium vivax occupies only $20 \%$ of infection (Nadjm et al., 2012). 
Table.1 Distibution of Patients among Malaria Infections

\begin{tabular}{|l|c|c|}
\hline Factor & No. of patients n=575 & Percantage \\
\hline 1. Gender & & \\
\hline a. Male & 313 & $54.43 \%$ \\
\hline b. Female & 262 & $45.5 \%$ \\
\hline 2. Age & 121 & $21.04 \%$ \\
\hline $1-10$ yr & 97 & $16.86 \%$ \\
\hline $11-20$ yr & 139 & $24.17 \%$ \\
\hline $21-30$ yr & 84 & $14.6 \%$ \\
\hline $31-40$ yr & 88 & $15.3 \%$ \\
\hline $41-50$ yr & 37 & $6.4 \%$ \\
\hline $51-60$ yr & 9 & $1.56 \%$ \\
\hline More than 60 yr & & \\
\hline 3.Locality & 401 & $69.73 \%$ \\
\hline Rural & 174 & $30.26 \%$ \\
\hline Urban & & \\
\hline 4.Educational status & 231 & $40.17 \%$ \\
\hline Educated & 344 & $59.82 \%$ \\
\hline Uneducated & & \\
\hline 5.Socio-economic status & 392 & $68.17 \%$ \\
\hline Katcha ghar & 183 & $31.82 \%$ \\
\hline Pacca ghar & & \\
\hline 6.Income & 117 & $20.34 \%$ \\
\hline Below poverty line & 458 & $79.65 \%$ \\
\hline Above poverty line & & \\
\hline 7.Outdoor/Indoor & 144 & $25.04 \%$ \\
\hline OPD & & \\
\hline IPD & & \\
\hline
\end{tabular}

Table No. 2 Month-wise distribution of Malaria infection

\begin{tabular}{|l|l|l|l|l|}
\hline Month & Pl. Vivax & Pl. Falciparum & Mixed infection & Total \\
\hline January & 4 & 1 & - & $5(0.86 \%)$ \\
\hline February & - & - & - & - \\
\hline March & - & - & - & - \\
\hline April & - & - & - & - \\
\hline May & - & - & - & - \\
\hline June & - & - & - & - \\
\hline July & 15 & 3 & - & $18(3.13 \%)$ \\
\hline August & 40 & 11 & & $51(8.86 \%)$ \\
\hline September & 154 & 41 & 7 & $202(35.1 \%)$ \\
\hline October & 183 & 73 & 3 & $259(45 \%)$ \\
\hline November & 21 & 9 & 1 & $31(5.39 \%)$ \\
\hline December & 8 & 1 & - & $9(1.56 \%)$ \\
\hline Total & $425(73.9 \%)$ & $139(24.6 \%)$ & $11(1.91 \%)$ & 575 \\
\hline
\end{tabular}


Table.3 Comparison of Various Studies from Various Places

\begin{tabular}{|l|l|l|l|}
\hline Study & Place & Pl falciparum & Pl. vivax \\
\hline Sidhu et al., 1991 & Kerala & $50 \%$ & $40.6 \%$ \\
\hline Anand et al., 1999 & North India & $85.36 \%$ & - \\
\hline Atif et al., 2000 & Pakistan & $26.6 \%$ & $66.6 \%$ \\
\hline Mishra et al., 2003 & Maharashtra & $59.09 \%$ & - \\
\hline Muddaiah et al., 2006 & Karnataka & - & $52.4 \%$ \\
\hline Jamaiah et al., 2006 & Malayshia & $57 \%$ & $38 \%$ \\
\hline Guera et al., 2010 & Africa & $22.6 \%$ & $42 \%$ \\
\hline Nadjm et al., 2012 & North America & $75 \%$ & $20 \%$ \\
\hline Alemu et al., 2012 & Ethopia & $75 \%$ & $25 \%$ \\
\hline Amit et al., 2012 & Gujrat & $66 \%$ & $34 \%$ \\
\hline Balpande et al., 2014 & Madhya Pradesh & $4.8 \%$ & $95.1 \%$ \\
\hline Swetha et al., 2015 & Gujrat & $4.13 \%$ & $95.83 \%$ \\
\hline Present study 2016 & Haryana & $24.6 \%$ & $73.9 \%$ \\
\hline
\end{tabular}

The limitation of this study was that we could not trace the malaria cases from remote area that did not attend the clinic; so, the actual prevalence of malaria and its epidemiological trend in Mewat region could not be calculated. Since most of patients were poor uneducated they live in mud plastered house and sleep in open places. In addition improper disposal of excreta stagnant water near houses working in field bare footed and with out clothing were major factors leading to transmission of malaria parasite.

The human behavioural pattern is a major epidemiological factor that impacts on disease transmission and progression.

Important component for reducing the burden of malarias morbidity and mortality include more sensitive diagnostic tools effective use of anti-malarial drugs and improved personnel and community protection and mosquito controls. In order to monitor the transmission of malaria and for eradication strategies, epidemiological studies of malaria are essential. There should be some policy and practice guidelines toward the factors that help in reducing the transmission.
Plasmodium vivax was reported as the most common parasite to cause malaria in Mewat region. Slide positivity rate were $12.7 \%$. Malaria was most common in male subjects than female subjects. The commonly affected age group was between 21 and 30 years. Water stagnation \& accumulation in rainy season plays a major role in mosquito breeding and subsequent spread of malaria. Poor sanitation in lower socioeconomic class has maximum number of malaria cases. With help of our study on malaria pattern we wish to create awareness at health sector level, municipal corporation level, Panchayat level and each individual level to take disciplinary action in monsoon season to prevent stagnation of water in our houses and colony. Government authority should find out the probable breeding sites of mosquitoes, slum areas, open drainage system etc which have to be cleaned regularly and water accumulation and stagnation should be avoided to prevent mosquito breeding. Individual awareness can create a miracle to stop transmission of malaria. Active vector control implementation of regular training programs, workshops and proper treatment should be encouraged to decrease transmission of malaria. 


\section{References}

Alemu A, Muluye D, Mihret M, Adugna M, Gebeyaw M. Ten year trend analysis of malaria prevalence in Kola Diba, North Gondar, Northwest Ethiopia. Parasit Vectors 2012;5:173.

Amit H. Agravat, Gauravi A. Dhruva , Khyati Babaria, Kalpesh Rathod Clinico-Hematological pattern of Malaria in Rajkot city, Gujrat, India. International Journal of Biomedical and Advance Research 2012; 03:11

Anand K., Kant S. and Kumar G Clinical case definition of malaria at a secondary level hospital in northern India. Southeast Asian Journal of Tropical Medical Public Health 1999; 30: $243-5$

Aruna Srivastava, B. N. Nagpal, Rekha Saxena, T. C. Wadhwa, Shiv Mohan, Gyanendra Pal Malaria epidemicity of Mewat region, District Gurgaon, Haryana, India: a GIS-based study Current Science 2004;86:9-10

Atif sitwat Hayat, Farzana memon Incidence and pattern of malaria infection at a tertiary care hospital of Hyderabad World Journal of Medical Science 2000;4:09-12

Balpande L, Gupta SK, Agarwal SS Epidemiological trends of malaria cases in rural health and training centre of Madhya Pradesh National Journal of Community Medicine 2014;5(2):227-9.

Chandrashekar UK, Sudharshan Murthy KA and Sunila. A study on clinical profile and outcome in falciparum malaria, Calicut Medical Journal 2011; 9:3

Chatterjee KD. Parasitology (Protozoology and Helminthology), 13th edn. New Delhi: CBS, 2012. pp. 90-127.

Chowta M.N. and Chowta K.N., Study of clinical profile of malaria at $\mathrm{KMC}$, Hospital Attavar, India, Journal of clinical and diagnostic research, 2007;3:110-115

Gauravi Mishra, Hospital based study of malaria in Ratnagiri district, Maharashtra, Journal of Vector Borne Disease, 2003; 109-111

Guerra CA, Howes RE, Patil AP, Gething PW, Van Boeckel TP, Temperley WH. The international limits and population at risk of Plasmodium vivax transmission in 2009. PLoS Neglected Tropical Disease 2010;4:774.

Jamaiah I, Rohela M, Nissapatorn V, MohamadAzlan $\mathrm{H}$, Nor Adli AR,ShahrulRizan I, Anez A, Jasmin B. A Retrospective Prevalence Study of Malariain an Aborigine hospital in Gombak, Selangor, Malaysia. Southeast Asian $j$ tropical medical public health.2006;37:1-4.

Joel JJ, Joshy P, Nair S, Shastry CS. A retrospective clinical based study of malaria in university teaching hospital. Journal Drug Delivary Therapeutics 2013;3(4):89-92.

Kumar A Praveen, Ramchandran R. Malaria associated factors in Thar Desert of Rajasthan, India: A case-control study. Journal of Rural Tropical Public Health 2010; 9: 6166.

Madhu Muddaiah and Prakash P.S., A study of clinical profile of malaria in a tertiary referral centre in South Canara, Journal of Vector Borne Disease, 2006;43:29-33

Nadjm B. and Behrens R.H., 'Malaria: An update for physicians', Infectious Disease clinics of North America,2012; 26:243-59

Park K., Text book of Preventive and Social Medicine,2002 XV111 edn; 193

Preetam N. Wasnik, Manohar T.P., Humaney N.R. and Sarkar H.R., Study of clinical profile of falciparum malaria in a tertiary referral centre in central India, Journal of the 
Association of Physician of India, 2012;60

Sidhu P.S, Ngsc. A retrospective study on malaria cases admitted to the University hospital, Kerala Lumpur, Medical Journal of Malaysia, 1991; 46: 177-82

Suman Bhattacharya, C. Sharma, R. C. Dhiman and A. P. Mitra Climate change and malaria in India Current Science 2006; 90:367-9

Sweta M Murawala, Vyoma Chudasama, Mahendra Vegad Prevalence of mosquito-borne Plasmodium infection in patients attending fever clinic in a tertiary-care teaching hospital, western India International Journal of Medical Science and Public Health 2015;4:11

Verma P, Shukla US, Kalraiya A. Retrospective study on clinical profile of severe malaria in children admitted in a tertiary care centre of central India. People's Journal Science Res 2014;7(1):22-6.

WHO world malaria report 2015.Geneva Switzerland world malaria report 2015 accessed on January 15, 2016.

\section{How to cite this article:}

Ruby Naz, Mohammad Khalid Farooqui, Ruchi Girotra and A. K. Malik. 2016. Pattern of Malaria Infection at Tertiary Care Hospital of Haryana-A Hospital Based Study. Int.J.Curr.Microbiol.App.Sci. 5(2): 330-337. doi: http://dx.doi.org/10.20546/ijcmas.2016.502.038 